\title{
Outcomes of fluoroscopy-free retrograde intrarenal surgery and predictive factors of stone-free
}

\author{
Huseyin Kocakgol ${ }^{1}$, Hasan Riza Aydin ${ }^{2}$, Ahmet Ozgur Guctas ${ }^{3}$, Cagri Akin Sekerci ${ }^{4}$, \\ Deniz Ozturk Kocakgol ${ }^{5}$, Hamit Zafer Aksoy ${ }^{2}$, Yiloren Tanidir ${ }^{6}$ \\ ${ }^{1}$ Department of Urology, University of Health Sciences, Erzurum Regional Training and Research Hospital, Erzurum, Turkey; \\ ${ }^{2}$ Department of Urology, University of Health Sciences, Kanuni Training and Research Hospital, Trabzon, Turkey; \\ ${ }^{3}$ Department of Urology, Marmara University Training and Research Hospital, Istanbul, Turkey; \\ ${ }^{4}$ Department of Urology, Division of Pediatric Urology, School of Medicine, Marmara University, Istanbul, Turkey; \\ ${ }^{5}$ Department of Radiology, Maresal Cakmak State Hospital, Erzurum, Turkey; \\ ${ }^{6}$ Department of Urology, School of Medicine, Marmara University, Istanbul, Turkey.
}

\begin{abstract}
Summary Objective: To evaluate the outcomes of flouroscopy-free retrograde intrarenal surgery (ffRIRS) and to investigate the factors that may affect stone-free rate.

Materials and methods: The charts of patients who underwent ffRIRS between January 2017 and August 2019 were reviewed retrospectively. Patients with missing preoperative imaging and patients with kidney anomalies were excluded from the study. Age, gender, stone size, stone localization, stone density, laterality, operation time, stone-free rate, complications and auxiliary procedures were recorded and analyzed.

Results: Study group involved 44 (43.1\%) female and 58

(56.8\%) male patients. Stone-free rate in a single-session ffRIRS were found to be correlated with stone localization $(p=0.003)$, stone volume $(p=0.004)$, and stone density $(p=0.009)$ but not with age $(p=0.950)$. Patients with multiple calyceal stones and a stone burden over $520 \mathrm{~mm}^{3}$ were found to be less stone-free.

The complication rate in female gender $(n=7)$ was significantly higher compared to male $(n=1)(p=0.011)$. No major complications such as ureteral injury or avulsion were observed. Overall, 13 patients (12.7\%) needed auxiliary procedures. The operation time seemed to be affected by stone size and gen$\operatorname{der}(p=0.005 ; p=0.044$, respectively).

Conclusions: Stone-free rate in ffRIRS were found to be affected by stone density, size, and localization. Patients with multiple caliceal stones and high stone burden $\left(<520 \mathrm{~mm}^{3}\right)$ have been found to have low stone-free rate, so one can speculate that having fluoroscopy assistance in RIRS might help us to improve surgical success.
\end{abstract}

KEY WORDS: Kidney stones; RIRS; Fluoroscopy free; Stone free; Stone density.

Submitted 12 August 2021; Accepted 28 October 2021

\section{INTRODUCTION}

In recent years, technological advances have provided us with important facilities in the surgical treatment of urinary tract stone diseases (UTSD). Open surgery has been largely replaced by minimally invasive urological procedures. Retrograde intrarenal surgery (RIRS), which is one of the minimally invasive techniques, differs from open sur- gery and percutaneous nephrolithotomy (PCNL) especially for avoidance of accessing to the renal cavities through the kidney cortex. Therefore, RIRS stands out as a better treatment option especially in avoiding some important complications such as bleeding and risk of injury of adjacent organs. However, minimally invasive stone surgery has potential problems, such as radiation exposure, for both the patient and the surgical team (1). Krup et al. reported their radiation exposure hypotheses according to a linear "non-threshold" model and estimated that one of every 1000 adult patients undergoing endoscopic stone surgery using fluoroscopy could experience secondary skin malignancy due to radiation exposure (2).

The present study, aimed to investigate the factors affecting the outcome of RIRS and stone-free rate in fluoroscopy-free technique setting.

\section{MATERIALS AND METHOdS}

After obtaining local ethics committee approval (ethics committee decision no: 1050), the charts of patients at the University of Health Sciences Trabzon Kanuni Training and Research Hospital, who underwent flouroscopy-free retrograde intrarenal surgery (ffRIRC) between January 2017 and August 2019 were reviewed retrospectively. Patients with missing preoperative non-contrast computed tomography (NCCT) and/or congenital kidney anomalies were excluded from the study. Computed Tomography (CT) scans of the patients were performed with a Siemens Somatom Emotion 16 detector device. Shooting protocol was in $1.5 \mathrm{~mm}$ axial sections with $110 \mathrm{kV}$ and $90 \mathrm{mAs}$ energy and images obtained in coronal and sagittal planes. The CT sections were evaluated in the window settings L300/W1120 and maximum stone length was measured in axial, coronal and sagittal axis. The stone burden was calculated with formula of the ellipsoid volume $(\pi / 6 \times \mathrm{D} 1 \times \mathrm{xD} 2 \mathrm{xD} 3)$ (3). A stone burden of $520 \mathrm{~mm}^{3}$ (when stone diameter was taken as $10 \mathrm{~mm}$ in all three planes) was used for comparison. Stone density was measured three times by taking more than 50\% of the stone size from the center of the stone. The average

No conflict of interest declared. 
Hounsfield Unit of three measurements was recorded as stone density (4). Stone density above and below 1000 HU was compared (5).

The "stone-free" condition was defined as absence of residual stones or presence of stone fragments less than $2 \mathrm{~mm}$. Stone features, demographic features, and surgical findings of patients like age, gender, stone size, stone localization, stone density, residual stone size and number, complications, operation time, stone-free rate, number and type of auxiliary procedures were analyzed and compared.

\section{Surgical technique}

All patients were evaluated preoperatively with physical examination, routine blood tests, urine test and culture, kidney-ureter-bladder $\mathrm{x}$-ray, and NCCT. The operation was performed when the urine culture was sterile and parenteral antibiotic prophylaxis was administered to all patients before the procedure. No medical expulsive treatment was given after the procedure. All patients were operated with the following standard equipment: 6/7.5 Fr Wolf ${ }^{\circledR}$ semirigid ureterorenoscope (URS), Storz ${ }^{\circledR}$ Flex-x $2 S$ flexible ureterorenoscope (f-URS), Wolf ${ }^{\circledR}$ Mega Pulse Tower $30+$ laser device and Cooks Medical ${ }^{\circledR} 10.7$ Fr ureteral access sheath (UAS). All operations were done under the general anesthesia. Initially a ureteroscopy was done in the dorsal lithotomy position with a semi-rigid URS with the aid of a guidewire. Semi-rigid ureteroscopy helped the passive dilation of the ureteral orifice and assessed the calibration and patency of the ureter. A $10.7 \mathrm{Fr}$ hydrophilic ureteral access sheath was gently advanced over the guidewire through the urethra into the ureters that look convenient for the UAS insertion. Fluoroscopyfree advancement of the UAS continue until any resistance was felt. In such cases, the guidewire was left on the patient and the UAS was taken out, and the lumen of the ureter was investigated with semi-rigid URS to assess the cause of resistance and possible ureter injury. In cases where UAS could not be placed, a double J stent was placed, and the procedure was terminated and postponed to another session.

After placing the UAS, the collecting system of the kidney was inspected with the f-URS and laser lithotripsy was performed. Laser settings were modified according to the efficiency of lithotripsy. Following lithotripsy, collecting system of the kidney was inspected for residual stones. FURS was carefully taken out of the body with the access sheath simultaneously and the guidewire was left within the ureter, so that the ureter was re-observed against any risk of injury. A double J stent was routinely placed into the renal pelvis in each patient. On the first postoperative day, a KUB X-ray was obtained, and the uneventful patients were discharged. Patients were re-evaluated by either ultrasonography (US) (n: 64) or NCCT (n:38) in the first postoperative month. Patients with significant residual stones or hydronephrosis were scheduled for auxiliary interventions.

\section{Statistical analysis}

Statistical analysis was done using International Business Machines (IBM) Statistical Package for Social Sciences (SPSS) Statistics for Windows (IBM Corp. Released 2017, Version
25.0. Armonk, NY: IBM Corp). Shapiro-Wilk test was used to evaluate the distribution of variables. Categorical variables were presented as numbers and percentages, and continuous variables as means and standard deviations. Categorical variables were analyzed using Chi-square test. Statistical analyses of the means of continuous variables were performed using Student's T-test and analysis of variance. A P-value of less than 0.05 was considered statistically significant.

\section{RESULTS}

A total of 102 patients, 44 female (43.1\%) and 58 male $(56.9 \%)$, were included in our study. The mean age of the study group was $48.4 \pm 14$. 4 years. In the primary procedure, RIRS was performed by placing a urethral sheath in $57(55.8 \%)$ patients. A double J stent was placed in the remaining 45 patients and RIRS was performed in the next session. Almost half of the patients had stones in renal pelvis ( $\mathrm{n}=55$, (53.9\%) (Table 1). Mean stone volume of patients were found to be $428 \pm 405 \mathrm{~mm}^{3}$.

Of all patients treated with ffRIRS, stone-free status was achieved in $69(67.6 \%)$. The mean age of these patients was similar to patients with residual stones $(48.3 \pm 14.4$ years vs $48.5 \pm 14.7$ years; $p=0.950$ ). Interestingly, stone free patients had a shorter operative time $(62.8 \pm 23.1$ minutes vs $80.5 \pm 24.5$ minutes; $\mathrm{p}=0.001$ ). Also, some stone characters were found to be significantly different in stone-free patients like stone localization ( $\mathrm{p}=0.003)$, size $(p=0.004)$ and density $(p=0.009)($ Table 1$)$.

No perioperative complications were found but eight patients ( 7 female, 1 male) suffered from postoperative complications. Majority of these patients $(n=4)$ had febrile urinary tract infection. Only one patient, required double J stent replacement in the postoperative early period. Three patients need a second look with URS/RIRS during stent removal due to high volume residual stones. Overall, a total of 13 patients underwent URS or RIRS as

\section{Table 1.}

Demographic features and parameters of stones ( $p$ values are for comparison of patients with and without residual stones).

\begin{tabular}{|c|c|c|c|c|}
\hline & $\begin{array}{c}\text { All patients } \\
(\mathrm{n}=102)\end{array}$ & $\begin{array}{c}\text { Stone-free } \\
\text { patients }(n=69)\end{array}$ & $\begin{array}{c}\text { Patients with residual } \\
\text { stones }(n=33)\end{array}$ & $P$ value \\
\hline$\overline{\text { Age (years) }}$ & $48.4 \pm 14.4$ & $48.3 \pm 14.4$ & $48.5 \pm 14.7$ & 0.950 \\
\hline $\begin{array}{l}\text { Gender } \\
\text { Female } \\
\text { Male }\end{array}$ & $\begin{array}{l}44(43.1 \%) \\
58(56.8 \%)\end{array}$ & $\begin{array}{l}33(47.8 \%) \\
36(52.1 \%)\end{array}$ & $\begin{array}{l}11(33.3 \%) \\
22(66.7 \%)\end{array}$ & 0.167 \\
\hline $\begin{array}{l}\text { Side } \\
\text { Right } \\
\text { Left }\end{array}$ & $\begin{array}{l}58(56.8 \%) \\
44(43.1 \%)\end{array}$ & $\begin{array}{l}42(60.9 \%) \\
27(39.1 \%)\end{array}$ & $\begin{array}{l}16(48.5 \%) \\
17(51.5 \%)\end{array}$ & 0.237 \\
\hline $\begin{array}{l}\text { Stone localization } \\
\text { Upper pole } \\
\text { Middle pole } \\
\text { Pelvis } \\
\text { Lower pole } \\
\text { Multiple }\end{array}$ & $\begin{array}{c}7(0.68 \%) \\
19(18.6 \%) \\
55(53.9 \%) \\
13(12.7 \%) \\
8(0.78 \%)\end{array}$ & $\begin{array}{c}3(4.3 \%) \\
14(20.3 \%) \\
43(62.3 \%) \\
8(11.6 \%) \\
1(1.4 \%)\end{array}$ & $\begin{array}{l}4(12.1 \%) \\
5(15.2 \%) \\
12(36.4) \\
5(15.2 \%) \\
7(21.2 \%)\end{array}$ & 0.003 \\
\hline $\begin{array}{r}\text { Stone volume } \\
<520 \mathrm{~mm}^{3} \\
>520 \mathrm{~mm}^{3} \\
\end{array}$ & $\begin{array}{l}77(75.4 \%) \\
25(24.6 \%)\end{array}$ & $\begin{array}{l}58(84.1 \%) \\
11(15.9 \%)\end{array}$ & $\begin{array}{l}19(57.6 \%) \\
14(42.4 \%)\end{array}$ & 0.004 \\
\hline $\begin{array}{c}\text { Stone density } \\
<1000 \mathrm{HU} \\
>1000 \mathrm{HU}\end{array}$ & $\begin{array}{c}53(\% 51.9) \\
49(\% 48)\end{array}$ & $\begin{array}{l}42(60.9 \%) \\
27(39.1 \%)\end{array}$ & $\begin{array}{l}11(33.3 \%) \\
22(66.7 \%)\end{array}$ & 0.009 \\
\hline
\end{tabular}


an auxiliary intervention. There was no statistically significant difference between the demographic or stone parameters of the patient who needed additional surgery ( $\mathrm{p}>0.05)$.

\section{Discussion}

The main goal of the treatment of UTSD is to provide stone-free with minimum harm and maximum benefit. Therefore, predictive factors are important in the selection of the treatment procedure. In this study, we investigated the need for fluoroscopy and predictive factors of RIRS.

It is a fact that fluoroscopy at many stages in the treatment of UTSD provides us with a roadmap function. However, ionizing radioactivity emitted from the X-ray device carries a potential risk for both the patient and the surgical team. Unfortunately, exposure to radioactivity does not have an exact threshold because the radioactive effect occurs in two ways with deterministic and stochastic effects. The detrimental effect occurs at radioactive exposure on the threshold dose.

The stochastic effect is the mutations caused by the effect of radiation on DNA and it is thought that there is no threshold value for this effect (6). Today, technological developments enable us to work with tools that provide smaller diameter and higher quality images in endourological interventions. In addition, ureteral injuries are more rare complications due to high-quality guide wires and ureteral access sheaths and expertise gained by urologists in endourological interventions.

Placing UAS during ffRIRS is one of the critical stages of the process. UAS provides direct access to the kidney during RIRS. However, it has been reported that it increases the susceptibility to urinary infection as well as ureteral injury (7). During UAS insertion, ureter damage may occur. Various techniques have been developed for the UAS placement procedure to prevent ureteral injury. Some authors recommend performing the procedure without UAS insertion, and others suggested placing UAS in pre-stented patients (8-10).

Boulalas et al. evaluated ureteral compliance with a $9.5 \mathrm{Fr}$ semi-rigid ureterorenoscopy routinely prior to 12/14 Fr UAS insertion in their prospective study. In patients with unsuitable small-diameter ureters, they continued the procedure with smaller-diameter instruments. In this series of 100 patients, UAS were successfully placed in the first session with this technique in 77 patients (77\%), but ureteral complications were reported in 10\%. Eight of these were reported as grade I secondary to $3 \mathrm{Fr}$ guide wire induction, and the remaining two as Grade I and Grade III ureteral injuries secondary to UAS procedure (11). In our study, UAS could be placed in 57 (55.8\%) patients at the first session in primary cases. We did not observe any complications related to ureteral injury. Routinely use of hydrophilic guidewire and a smaller diameter of 10.7 Fr UAS could explain this result. In addition, some Authors described the technique of wearing UAS on semi-rigid or flexible URS (12-13).

The benefits of performing sheath placement under fluoroscopy are controversial, because fluoroscopy without the administration of opaque material has no ability to show strictures, kinks, or non-opaque stones in the ureter. Wearing a UAS on the URS allows direct visualization of the ureter during the procedure. However, using the ureteroscope instead of the access sheath mandrel may cause the loss of the protection of the ureteral wall due to the mandrel that is a "non-traumatic, round structure that completely covers the sheath mouth".

In our study, ffRIRS was applied to eligible patients in the first session, whereas non eligible patients were treated in a second session after double J stent.

Various studies have been conducted on the treatment of ffRIRS. In a series of 100 patients, 33 patients underwent the procedure with fluoroscopy, while in 67 patients the procedure was done without fluoroscopy and no statistically significant difference was reported between the two groups in terms of perioperative complications. In the same study, there were no major complications such as ureter perforation, and no statistically significant difference was reported between stone-free rates (14).

In another study in which RIRS was performed without using fluoroscopy a total of 5 complications ( 5 fever, 1 hematuria) in 140 patients were reported and a high stone-free rate of $95.7 \%$ was reported (6).

When we searched the literature about RIRS, we did not find a study in which age, gender and side factor were found to be significant in providing stone free. In the study of Resorlu et al., patients were evaluated in four different age groups as $\leq 7,8-17,18-60$, and $>60$ years old and there was no statistically significant difference in stone-free rates between patient groups (15). Similarly, Soo Hyun Lim et al. did not report age and gender as a predictive factor in their study (16). In our study, the mean age of patients without residual stones was $48.3 \pm 14.4$ years, and the mean age of patients with residual was $48.5 \pm 14.7$ years $(p=0.950)$. Although our stone free rate was $75 \%$ in females and $62.1 \%$ in males, there was no statistically significant difference $(\mathrm{p}=0.121)$.

In many studies, stone size has been reported as an important predictive factor of success of RIRS $(15,16)$. However, the fact that the stone-free ratio tend to be lower with the increase in stone size does not mean that RIRS can be completely avoided in these patient groups. In EAU guidelines, total stone-free rates of $91 \%$ have been reported with 1.45 procedures in patients with stones over $2 \mathrm{~cm}$ (1719). We calculated stone size as $\mathrm{mm}^{3}$ aiming to have a more accurate evaluation of stone size. In our study, the rate of stone-free after one session was $75.2 \%$ in the patient group with a stone size $<520 \mathrm{~mm}^{3}$, while it was $44 \%$ in the group $>520 \mathrm{~mm}^{3}(\mathrm{p}=0.005)$.

Stone localization and infundibulo-pelvic angle have been reported as important predictive factors in the RIRS procedure. Resorlu et al. reported that stone-free ratio was statistically decreased in lower pole stones, multi-calyceal stones and in patients with infundibulo-pelvic angle $<45^{\circ}$ (15). Sung Yong Cho et al. reported that stone-free rates in multiple stones were statistically lower than in single stone in their study $(\mathrm{p}=0.005)(20)$.

The results of our study were compatible with the literature. Our stone-free rates were $73.7 \%$ and $78.2 \%$ in the middle pole and pelvis stones and were $61.5 \%, 42.9 \%$ and $12.5 \%$ in the lower pole, upper pole and multiple stones, respectively $(p=0.003)$. 
Table 2.

The comparison of studies with fluoroscopy assisted retrograde intrarenal surgery and present study

\begin{tabular}{|c|c|c|c|c|c|c|}
\hline $\begin{array}{l}\text { Author/year } \\
\text { Study design }\end{array}$ & $\begin{array}{l}\text { Lim S.H. et al. } 2010 \text { (16) } \\
\text { Retrospective }\end{array}$ & $\begin{array}{c}\text { Resorlu et al. } 2012 \text { (15) } \\
\text { Retrospective }\end{array}$ & $\begin{array}{l}\text { Ito H. et al. } 2014 \text { (27) } \\
\text { Retrospective }\end{array}$ & $\begin{array}{l}\text { Erbin A. et al. } 2016 \text { (28) } \\
\text { Retrospective }\end{array}$ & $\begin{array}{l}\text { Xiao et al. } 2017 \text { (25) } \\
\text { Retrospective }\end{array}$ & $\begin{array}{l}\text { Present study } \\
\text { Retrospective }\end{array}$ \\
\hline Number of patients (n) & 66 & 207 & 310 & 339 & 382 & 102 \\
\hline Stone free rate $(\%)$ & $72.7 \%(46 / 66)$ & $\% 86(178 / 207)$ & $59.6 \%(185 / 310)$ & $70.1 \%(238 / 339)$ & $73.6 \%(281 / 382)$ & $67.6 \%(69 / 102)$ \\
\hline Stone localization & $\begin{array}{l}\text { Upper-middle pole or pelvis: } \\
\text { SFR: } 94.2 \%(17 / 18) \\
\text { Lower pole: } \\
\text { SFR: } 60.4 \%(29 / 48) \\
\text { (P: } 0.007)\end{array}$ & $\begin{array}{l}\text { Upper-middle pole: } \\
\text { SFR: 92.7\% (51/55) } \\
\text { Pelvis: } \\
\text { SFR: } 90.6 \% \text { (58/64) } \\
\\
\text { Lower pole: } \\
\text { SFR: } 78.4 \% \text { (69/88) } \\
\text { (P: } 0.025)\end{array}$ & $\begin{array}{l}\text { Lower pole stone presence: } \\
\text { SF Group: } 53.5 \%(99 / 185) \\
\text { Non-SF group: } \\
85.6 \%(107 / 125) \\
(P<0.001)\end{array}$ & $\begin{array}{c}\text { Upper calyx: } \\
\text { SFR: } 72.2 \%(26 / 36) \\
\text { Middle calyx: } \\
\text { SFR: } 92.9 \%(13 / 14) \\
\text { Pelvis: } \\
\text { SFR: } 73.1 \%(76 / 104) \\
\text { Lower calyx: } \\
\text { SFR: } 65.5 \% \text { (91/139) } \\
\text { Multiple calyces: } \\
\text { SFR: } 69.6 \%(32 / 46) \\
\text { (P: } 0.247) \\
\text { Lower pole infindibulopelvic angle: } \\
\text { SF Group: } 49.5^{\circ} \pm 12.3^{\circ} \\
\text { Non-SF Group: } 44.1^{\circ} \pm 11.3^{\circ} \\
\text { (P: } 0.004)\end{array}$ & $\begin{array}{l}\text { Inferior pole stone group: } \\
\text { SF Group: } 47.6 \%(69 / 145) \\
\text { Non-Inferior pole stone free group: } \\
89.5 \%(212 / 237) \\
(P<0.001) \\
\text { Single stone group: } \\
\text { SFR: } 85.8 \%(200 / 233) \\
\text { Multiple calyces stone group: } \\
\text { SFR: } 54.4 \%(81 / 149) \\
(P<0.001)\end{array}$ & $\begin{array}{c}\text { Upper pole } \\
\text { SFR: } 42.8 \%(3 / 7) \\
\text { Middle pole } \\
\text { SFR: } 73.6 \%(14 / 19) \\
\text { Pelvis: } \\
\text { SFR: } 78.1 \% \text { (43/55) } \\
\text { Lower pole: } \\
\text { SFR: } 61.5 \%(8 / 13) \\
\text { Multiple: } \\
\text { SFR: } 12.5 \%(1 / 8) \\
\text { (P: } 0.003)\end{array}$ \\
\hline Stone size & $\begin{array}{c}\leq 150 \mathrm{~mm}^{2} \\
\text { SFR: } 83.7 \%(41 / 49) \\
>150 \mathrm{~mm}^{2} \\
\text { SFR: } 29.4 \%(5 / 17) \\
\quad(P<0.001) \\
\text { SF group: } 12 \mathrm{~mm}(9-17)\end{array}$ & \begin{tabular}{|c|}
$0-10 \mathrm{~mm}$ SFR: $88.9 \%(8 / 9)$ \\
$11-20 \mathrm{~mm}$ \\
SFR: $93.3 \%(153 / 164)$ \\
$>20 \mathrm{~mm}$ SFR: $50 \%(17 / 50)$ \\
$\quad(\mathrm{P}<0.001)$
\end{tabular} & $\begin{array}{l}\text { SF group: } 15.88 \mathrm{~mm} \\
\text { Non-SF group: } \\
32.79 \mathrm{~mm} \\
P<0.001\end{array}$ & $\begin{array}{c}\text { SF group: } 13.6 \pm 4.7 \mathrm{~mm} \\
\text { Non-SF group: } 16.4 \pm 6.5 \mathrm{~mm} \\
(\mathrm{P}: 0.000)\end{array}$ & $\begin{array}{l}\text { Mean stone size: } 14 \mathrm{~mm} \\
\text { SF group: } 12 \mathrm{~mm}(9-17) \\
\text { Non-SF group: } 25 \mathrm{~mm}(18-29) \\
\quad(P<0.001)\end{array}$ & $\begin{array}{c}<520 \mathrm{~mm}^{3} \\
\text { SFR: } 75.3 \%(58 / 77) \\
>520 \mathrm{~mm}^{3} \\
\text { SFR: } 44 \%(11 / 25) \\
(P: 0.004)\end{array}$ \\
\hline $\begin{array}{l}\text { Stone density (HU) } \\
\text { (HU) }\end{array}$ & $\mathrm{NA}$ & $\mathrm{NA}$ & $\begin{array}{c}\text { SF group: } \\
944.49 \text { (373.52) HU } \\
\text { Non-SF group: } 1099.73 \\
(335.46) \text { HU } \\
(P<0.001)\end{array}$ & $\mathrm{NA}$ & $\begin{array}{c}\text { SF group: } \\
1022.59 \pm 342.97 \text { HU } \\
\text { Non-SF group: } \\
1193.43 \pm 285.44 \text { HU } \\
(P<0.001)\end{array}$ & $\begin{array}{c}<1000 \text { HU } \\
\text { SFR: } 79.2 \%(42 / 53) \\
>1000 \text { HU } \\
\text { SFR: } 55.1 \%(27 / 49) \\
\text { (P: } 0.009)\end{array}$ \\
\hline Operation time (min) & $\mathrm{NA}$ & $52(15-95)$ & $\mathrm{NA}$ & $\mathrm{NA}$ & $\begin{array}{c}\text { SF group: } \\
50(60-40 ; 20) \text { min. } \\
\text { Non-SF group: } \\
60(85-50 ; 35) \text { min. } \\
(P<0.001)\end{array}$ & $64.7 \pm 23.2$ \\
\hline Complication rate (\%) & $4(6 \%)$ & $20(9.66 \%)$ & $18(5.8 \%)$ & $18(5 \%)$ & $27(7.1 \%)$ & $8(7.8 \%)$ \\
\hline $\begin{array}{l}\text { Type of } \\
\text { complication cases (n) }\end{array}$ & $\begin{array}{c}\text { Intraoperative minor } \\
\text { ureter injury (1) } \\
\text { Febrile urinary tract infection (2) } \\
\text { Postoperative paralytic ileus (1) }\end{array}$ & $\begin{array}{l}\text { Ureteral perforation (1) } \\
\text { Abdominal pain (4) } \\
\text { Voiding disturbances (4) } \\
\text { Hematuria (4) } \\
\text { Postoperative fever } \\
\text { or infection (5) } \\
\text { Urosepsis (1) }\end{array}$ & $\begin{array}{l}\text { High-grade postoperative } \\
\text { fever (16) } \\
\text { Postoperative ureteric } \\
\text { stricture (2) }\end{array}$ & $\begin{array}{c}\text { Clavien grade I } \\
\text { or II complication (12) } \\
\text { Clavien grade IIIA } \\
\text { complication (urosepsis) (7) }\end{array}$ & $\mathrm{NA}$ & $\begin{array}{c}\text { Clavien grade l: } \\
\text { Febrile urinary } \\
\text { tract infection (4) } \\
\text { Clavien grade IIIB: } \\
\text { URS was performed } \\
\text { due to a residual } \\
\text { ureter stone that could } \\
\text { not pass (4) }\end{array}$ \\
\hline
\end{tabular}

Stone density was another important parameter in treatment of renal stones. This parameter has found its place in many studies especially on extracorporeal lithotripsy $(21,22)$. Kim et al. reported that stone density did not affect the endoscopic treatment of ureteral stones (23). In the treatment of ureteral stones, it should be considered that a thicker laser probe can be used with the semirigid URS and that it can be easily manipulated.

Predictive effect of the stone density in RIRS is controversial and there are a limited number of studies in the literature. Gucuk et al. found stone density to be insignificant as a predictive factor in RIRS treatment $(\mathrm{p}=0.22)$.

In this article, unlike the present study, the stones were divided as below and above $677 \mathrm{HU}$ (24). In another study, stone density was evaluated in groups of patients with and without stone free and it was found to be higher in patients with residual stone $(\mathrm{p}<0.001)$ but a density limit was not specified (25). In our study, stone density was found to be a predictive factor in stone-free when patients who underwent RIRS were evaluated according to two different categories of stone density $(<1000 \mathrm{HU}$ and $>1000 \mathrm{HU}$ ): stone-free rate was $55.1 \%$ in patients with stone density above $1000 \mathrm{HU}$ and $79.2 \%$ in the group below $1000 \mathrm{HU}(\mathrm{p}=0.009)$.

In our study, the gender was found to be a significant factor in the development of complications. No statistically 
significant difference was observed in other parameters. Seven of our 8 patients who developed complications were women $(p=0.04)$. Febrile urinary tract infection developed in 4 patients (Clavien grade I) and they were treated with appropriate antibiotics and antipyretic therapy. All the patients with febrile urinary infection were female. We think that this finding may be related to the fact that women are more prone to urinary tract infection (26). Complications requiring surgical intervention (Clavien grade 3B) developed in 4 patients and URS was performed due to a residual ureter stone that could not pass.

A total of 13 patients underwent URS/RIRS as an additional intervention. 4 of them were secondary to complications, and the remaining 9 patients received RIRS treatment as second session. The 18 of the remaining patients who were not stone free were included in the follow-up protocol. In 11 of 13 patients who needed additional treatment, stone density was $>1000 \mathrm{HU}(\mathrm{p}=0.08)$.

In our study, the operation time was found to be significantly longer in high stone volume and men. While mean operation time was $64.7 \pm 23.2$ minutes in the patient group with stone burden $<520 \mathrm{~mm}^{3}$, it was $80.4 \pm 26.6$ minutes in the patient group with $>520 \mathrm{~mm}^{3}(\mathrm{p}=0.005)$. Similarly, the operation time was found to be longer in the non-stone free group $(\mathrm{p}=0.001)$. Operation time in females was $62.8 \pm 19.6$ minutes and $72.8 \pm 27.6$ minutes in males ( $\mathrm{p}=0.044)$. It is not surprising that the operation time is longer in high stone volume. However, it is noteworthy that the duration of the operation in women is shorter. In our study, we think that the short female urethra and the low number of female patients with a stone size $>520 \mathrm{~mm}^{3}$ (n: 8) are an explanation of this result. The operation time was found to be $64.3 \pm 25.5$ minutes in patients with $<1000 \mathrm{HU}, 73.1 \pm 23.6$ minutes in patients with $>1000 \mathrm{HU}(\mathrm{p}=0.07)$.

We summarized the results of some fluoroscopy assisted RIRS studies and our findings in Table 2. We choose these studies as the stone burden seemed to be similar to ours. Our stone-free rates are lower than those observed in these studies although complication rates were similar or lower. As an exception, Ito et al. reported worse stone free rates and almost similar complication rates, but in this series the majority of stones were in the lower pole (15, $16,25,27,28)$. A randomized comparison should be necessary to confirm that fluoroscopy-free RIRS can obtain the same results of conventional RIRS with the use of fluoroscopy.

The study has some limitations. This was a retrospective study, and all controls were not performed with CT. Our study has no control group, so it lacks the comparison with data of fluoroscopy assisted RIRS. We tried to get rid of this limitation by comparing our study with historical fluoroscopy assisted RIRS studies as shown in Table 2.

\section{Conclusions}

Although fluoroscopy is not protective against major complications such as ureteral injury, it may increase success in multiple calyx and large stones. Stone density, size, and localization were observed to affect the success of treatment. Particularly, stone density occurred as an important predictive factor for RIRS in this study. We hope that our study will make an important contribution to the literature, evaluating ffRIRS and stone density as predictive factor.

\section{References}

1. Olgin G, Smith D, Alsyouf $M$, et al. Ureteroscopy without fluoroscopy: a feasibility study and comparison with conventional ureteroscopy. J Endourol. 2015; 29:625-9.

2. Krupp N, Bowman R, Tenggardjaja C, et al. Fluoroscopic organ and tissue-specific radiation exposure by sex and body mass index during ureteroscopy. J Endourol. 2010; 24:1067-73.

3. Park J, Kang M, Jeong CW, et al. External validation and evaluation of reliability and validity of the modified seoul national university renal stone complexity scoring system to predict stone-free status after retrograde intrarenal surgery. J Endourol. 2015; 29:888-93.

4. Foda K, Abdeldaeim H, Youssif M, Assem A. Calculating the number of shock waves, expulsion time, and optimum stone parameters based on noncontrast computerized tomography characteristics. Urology. 2013; 82:1026-31.

5. Cakiroglu B, Eyyupoglu SE, Tas T, et al. Are Hounsfield densities of ureteral stones a predictive factor for effectiveness of extracorporeal shock wave lithotripsy? Int J Clin Exp Med. 2014; 7:1276.

6. Peng $Y, X u B$, Zhang W, et al. Retrograde intrarenal surgery for the treatment of renal stones: is fluoroscopy-free technique achievable? Urolithiasis. 2015; 43:265-70.

7. Karaaslan M, Tonyali S, Yilmaz M, et al. Ureteral access sheath use in retrograde intrarenal surgery. Arch Ital Urol Androl. 2019; 91:112-114

8. Emiliani E, Motta G, Llorens E, et al. Totally fluoroless retrograde intrarenal surgery technique in prestented patients: tips and tricks. $J$ Pediatr Urol. 2019; 15:570-3.

9. Tepeler A, Armagan A, Akman T, et al. Is fluoroscopic imaging mandatory for endoscopic treatment of ureteral stones? Urology. 2012; 80:1002-6.

10. Hein S, Schoenthaler $M$, Wilhelm $K$, et al. Ultralow radiation exposure during flexible ureteroscopy in patients with nephrolithiasis-How far can we go? Urology. 2017; 108:34-9.

11. Boulalas I, De Dominicis M, Defidio L. Semirigid ureteroscopy prior retrograde intrarenal surgery (RIRS) helps to select the right ureteral access sheath. Arch Ital Urol Androl. 2018; 90:20-4.

12. Ekici M, Özgür BC, Ssentürk AB, et al. All-seeing-access sheath: A novel fluoroscopy-free placement technique in retrograde intrarenal surgery. J Coll Physicians Surg Pak. 2019; 29:263-267.

13. Sönmez MG, Kara C. A new approach in ureteral access sheath locating in retrograde intrarenal surgery (RIRS) by endovisional technique. Arch Ital Urol Androl. 2015; 87:286-90.

14. Manzo BO, Lozada E, Manzo G, et al. Radiation-free flexible ureteroscopy for kidney stone treatment. Arab J Urol. 2019; 17:200205.

15. Resorlu B, Unsal A, Gulec H, Oztuna D. A new scoring system for predicting stone-free rate after retrograde intrarenal surgery: the "resorlu-unsal stone score". Urology. 2012; 80:512-8.

16. Lim SH, Jeong BC, Seo SI, et al. Treatment outcomes of retrograde intrarenal surgery for renal stones and predictive factors of stonefree. Korean J Urol. 2010; 51:777-82.

17. Wendt-Nordahl G, Mut T, Krombach P, et al. Do new generation flexible ureterorenoscopes offer a higher treatment success than their predecessors? Urol Res. 2011; 39:185-8. 
18. Geraghty R, Abourmarzouk O, Rai B, et al. Evidence for ureterorenoscopy and laser fragmentation (URSL) for large renal stones in the modern era. Curr Urol Rep. 2015; 16:54.

19. Binbay M, Yuruk E, Akman T, et al. Is there a difference in outcomes between digital and fiberoptic flexible ureterorenoscopy procedures? J Endourol. 2010; 24:1929-34.

20. Cho SY, Choo MS, Jung JH, et al. Cumulative sum analysis for experiences of a single-session retrograde intrarenal stone surgery and analysis of predictors for stone-free status. PloS one. 2014; 9:e84878.

21. Wang L-J, Wong Y-C, Chuang C-K, et al. Predictions of outcomes of renal stones after extracorporeal shock wave lithotripsy from stone characteristics determined by unenhanced helical computed tomography: a multivariate analysis. Eur Radiol. 2005; 15:2238-43.

22. El-Nahas AR, El-Assmy AM, et al. A prospective multivariate analysis of factors predicting stone disintegration by extracorporeal shock wave lithotripsy: the value of high-resolution noncontrast computed tomography. Eur Urol. 2007; 51:1688-94.

23. Kim JW, Chae JY, Kim JW, et al. Computed tomography-based novel prediction model for the stone-free rate of ureteroscopic lithotripsy. Urolithiasis. 2014; 42:75-79.

24. Gucuk A, Yilmaz B, Gucuk S, Uyeturk U. Are stone density and location useful parameters that can determine the endourological surgical technique for kidney stones that are smaller than $2 \mathrm{~cm}$ ? A prospective randomized controlled trial. Urol J. 2019; 16:236-41.

25. Xiao Y, Li D, Chen L, et al. The R.I.R.S. scoring system: An innovative scoring system for predicting stone-free rate following retrograde intrarenal surgery. BMC Urology. 2017; 17:105.

26. Harrington RD, Hooton TM. Urinary tract infection risk factors and gender. The journal of gender-specific medicine: JGSM: the official journal of the Partnership for Women's Health at Columbia. 2000; 3:27-34.

27. Ito, H, Sakamaki K, Kawahara T, et. al. Development and internal validation of a nomogram for predicting stone-free status after flexible ureteroscopy for renal stones. BJU International. 2015; 115: 446-451.

28. Erbin A, Tepeler A, Buldu I, et al. External comparison of recent predictive nomograms for stone-free rate using retrograde flexible ureteroscopy with laser lithotripsy. J Endourol. 2016, 30: 1180-1184.

\section{Correspondence}

Huseyin Kocakgol, MD (Corresponding Author)

hsynkocakgl@gmail.com

Department of Urology, University of Health Sciences, Erzurum Regional

Training and Research Hospital, Adnan Menderes Mahallesi Ssehit Burak Karakus

Sokak Al-Furkan Sitesi A Blok Kat:1 No:8 Palandöken/Erzurum (Turkey)

Hasan Riza Aydin, MD

hasanriza.aydin.61@gmail.com

Hamit Zafer Aksoy, MD

hamitzaferaksoy@hotmail.com

Department of Urology, University of Health Sciences, Kanuni Training

and Research Hospital, Trabzon (Turkey)

Ahmet Ozgur Guctas, MD

aoguctas@gmail.com

Department of Urology, Marmara University Training and Research Hospital,

Istanbul (Turkey)

Cagri Akin Sekerci, MD

cagri_sekerci@hotmail.com

Department of Urology, Division of Pediatric Urology, School of Medicine,

Marmara University, Istanbul (Turkey)

Deniz Ozturk Kocakgol, MD

dr.denizz@hotmail.com

Department of Radiology, Maresal Cakmak State Hospital, Erzurum (Turkey)

Yiloren Tanidir, MD

yiloren@yahoo.com

Department of Urology, School of Medicine, Marmara University, Istanbul (Turkey) 